\title{
Standardization and Quality Evaluation of Spray Dried Flavored Lassi Powder
}

\author{
H.W. Deshpande ${ }^{1^{*}}$, S.L. Waikar ${ }^{2}$ and S.D. Katke ${ }^{1}$ \\ ${ }^{1}$ Dept. of Food Microbiology \& Safety, College of Food Technology, \\ VNMKV, Parbhani, India \\ ${ }^{2}$ Dept. of Soil Science \& Agricultural Chemistry, College of Agriculture, \\ VNMKV, Parbhani, India \\ *Corresponding author
}

A B S T R A C T

\section{Keywords}

Lassi, flavored lassi, Buttermilk, soymilk, Lactic acid bacteria,

Streptococcus thermophilus, Lactobacillus bulgaricus, Streptococcus lactis,

Streptococcus diacetylactis

Article Info

Accepted:

10 July 2020

Available Online:

10 August 2020
The present study was planned to prepare the flavored lassi with the blending of buttermilk and soymilk at different concentrations and the prepared product has been evaluated by trained judges on the basis of 9 point Hedonic scale. The prepared product was evaluated for its color and appearance, flavor, body and texture, taste and overall acceptability of the final product. The flavored lassi prepared $70 \%$ buttermilk and 30\% soymilk with addition of sugar (15\%) and mango pulp (5\%) got the highest overall acceptability by the panel members than other treatments. Then the flavored lassi was spray dried for preparation of powder. Results obtained from nutritional quality of lassi powder have been proven that lassi powder is rich source of vitamin A and minerals like calcium, phosphorus. Reconstitution properties of prepared lassi powder were found to be best.

\section{Introduction}

Milk is the most wholesome single food available in nature for health and medicine, which has never been debated. It is rich in nutritive value and important source of food for human. Milk is the most precious liquid food in nature and supplies body building proteins, bone forming minerals, health giving vitamins and energy giving lactose and milk fat. India has highest milk production in the world i.e.121.8 million tones with per capita availability of $281 \mathrm{gm} /$ day (GOI, 2012). A fermented milk product also known as cultured dairy foods. The cultured dairy products or cultured milk products are dairy 
foods that have been fermented with lactic acid bacteria such as Lactobacillus, Leuconostoc and Lactococcus fermentation process, which increases the shelf life product as well as add the taste and improves the digestibility of milk. About $9 \%$ of the total milk produced in India is converted into fermented milk products (Singh, 2007).

Lassi is a fermented beverage generally made from curd obtained by lactic acid culture to which sugar or salt are added. Lassi is a popular and traditional yoghurt based drink which is originated in Punjab region of the Indian sub-continent. It is made by blending yoghurt with water, salt, pepper, ice and Indian spices. Lassi is taken cold and is a good way to beat the scorching heart and get refreshed. In addition, it is considered to be a healthy drink. Lassi is one of the finest, unique and refreshing summer coolants. A plain lassi is just made by thick curd or yoghurt, salt or sugar, ice cubes and water. Lassi can be customized in any way you like by adding tropical fruits such as mango, strawberries etc, to enhance the flavor and taste and making it refreshing and delightable. Excellent quality lassi can be produced by blending lassi with $20 \%$ pomegranate juice had lowest juice (Avtade et al., 2010). The production of lassi has been confined, to a large extent, to the households and local halwais mainly because of non-availability of a standardized technique for the manufacture of uniform quality lassi and its limited shelf life. In 1972 the technology was standardized at National Dairy Research Institute, Karnal and regular production of lassi started. Blended lassi was prepared from soya milk of two varieties of soyabean, Pratishta (MAUS61-2) and Sumrudhi (MAUS-71), with skim milk powder (SMP) and buffalo milk (BM). Both the soyabean varieties were found suitable for soya milk blended lassi. (Kadam et al., 2005, 2006)
The major byproducts of the dairy industry are skim milk, buttermilk and whey. Buttermilk is one the products of the dairy drinks. Originally buttermilk was the liquid left behind after churning butter out of cream. Buttermilk controls the vitiation of all three and is nutritive, freshening and appetizing in action. It is highly acclaimed medicine for diarrhea, dysentery, chronic specific and nonspecific colitis, piles and jaundice and also in conditions where liver and spleen dysfunctions are involved. Buttermilk has been used in gastrointestinal upsets since time immemorial (Anon, 2003). Buttermilk is good dietary source of calcium not only because of its high calcium content, but also because calcium becomes solubilized due to the acidic $\mathrm{pH}$ thus improving the bio-availability. Buttermilk is reported to be containing more latent "taurine" than the milk or curd itself (Balsubramanya, 2002).

Soybean is the concentrated source of vegetable proteins. It contains generally about $40 \%$ protein. Soybean has occupied a unique position in the diet of Indian population. It can be processed to produce a texture and appearance similar to many other foods. For example, soybeans are the primary ingredient in many dairy product substitutes e.g., soy milk, margarine, soy ice cream, soy yoghurt, soy cheese and soy cream cheese. Soymilk may play a more important role in keeping the heart healthy than bovine milk (Odo, 2003; U. S. Soyfoods Directory, 2007). Soymilk has a great potential to supplement the dairy milk and its nutritional comparability with mother milk and cow milk. Soymilk has been advocated as a low cost high protein beverage suitable for developing countries. Recipes from freshly extracted soymilk like ice-cream, kalakand, and pudding, soy channa and kadhi and shrikhand from soy curd were prepared. Soymilk is being free from cholesterol, gluten and lactose. Soymilk is a suitable food for lactose-intolerant consumers, vegetarians and 
milk allergy patients (Liu and Lin, 2000). Soymilk is promoted as a healthy alternative to cow or buffalo milk. It has diabetes management ability to control blood sugar levels, source of lecithin and vitamin $\mathrm{E}$, but lack in casein. The iron content of soymilk is 12 times higher than that of bovine and human milk, and so it is effective in treating anemia (Odo, 2003; Fehily, 2003). It is also safe for people with milk allergy. Also soymilk contains isoflavones and organic chemicals which are beneficial to health. Soymilk may play a more important role in keeping the heart healthy than bovine milk (U.S. Soy foods Directory, 2007).

\section{Materials and Methods}

The fresh buffalo milk was obtained from the local market. The milk was used for preparation of buttermilk. Soybeans, sugar, mango pulp and guar gum were procured form local market.

\section{Preparation of buttermilk}

A good quality buffalo milk was standardized to fat $(6 \%)$ heated to about $85^{\circ} \mathrm{C}$ for $15 \mathrm{~min}$, immediately cooled to $40^{\circ} \mathrm{C}$ and inoculated with starter culture (lactic acid bacteria, Streptococcus thermophilus, Lactobacillus bulgaricus, Streptococcus lactis and Streptococcus diacetylactis 1-2 \%). Then it was incubated at room temperature for about $12-14 \mathrm{~h}$, till the desired acidity in the curd was obtained.

The curd was then churned by using traditional churner. Simultaneously desired temperature of about $50^{\circ} \mathrm{F}$ was maintained by adding required quantity of pasteurized chilled water and the butter was collected from the surface and the remaining liquid was collected as buttermilk. It was passed through cream separator to remove residual butter or fat.

\section{Preparation of soy milk}

Soymilk was prepared as per the procedure given by Srilakshmi (2003). It was prepared by soaking beans in $(0.5 \%)$ sodium bicarbonate solution at room temperature for overnight. The soaking solution was three times of weight of clean soybean taken. Then the soaked water was drained and beans was blanched in fresh water for $30 \mathrm{~min}$. The hulls were then removed by rubbing. The dehulled beans were grained with hot water in mixer and diluted finally to 1:6 ratios on dry basis. The wet mass was cooked for $20-25 \mathrm{~min}$ at $100^{\circ} \mathrm{C}$ and filtered through three folds of muslin cloth.

\section{Preparation of dahi}

Dahi was prepared by using following procedure given by De (2006). The buttermilk was taken which was obtained from buffalo milk. The prepared milk was preheated (35$40^{\circ} \mathrm{C}$ ) and standardized. The soymilk prepared from soybean was preheated at 35$40^{\circ} \mathrm{C}$ and stand. Both milks were then mixed together according to the treatment combination. This mixture was then heated to $80-90^{\circ} \mathrm{C}$. Then it was allowed to cool up to $20-30^{0} \mathrm{C}$. The previously prepared dahi was added in the mixture as culture at the rate of one to two tablespoon. The mixture was incubated at room temperature for $10-12 \mathrm{~h}$ and $d a h i$ was obtained.

\section{Preparation of Lassi}

Lassi was prepared by using following procedure given by De (2006). The prepared dahi as per the treatment combination was taken separately and continuously stirred. The grinded sugar was added in dahi at the rate of $13-15 \%$. Then dahi was continuously stirred again for the proper mixing of sugar and to break the lumps. The mango pulp was added at the rate of $5 \%$. The prepared lassi was been 
filled in bottles or pouches and stored at refrigerated temperature.

\section{Treatments for lassi}

For preparation of flavored lassi following blends of buttermilk and soymilk were used.

$\mathrm{A}=100 \%$ buttermilk (Control)

$\mathrm{B}=80$ parts of buttermilk +20 parts of soymilk

$\mathrm{C}=70$ parts of buttermilk +30 parts of soymilk

$\mathrm{D}=60$ parts of buttermilk +40 parts of soymilk

\section{Preparation of flavored lassi powder}

The flavored lassi is prepared as per procedure and flavored lassi powder is prepared by using spray drier.

\section{Results and Discussion}

\section{Physico-chemical characteristics of buttermilk and soymilk}

The Physico-chemical characteristics of buttermilk and soymilk were presented Table 1.

The $\mathrm{pH}$ of buttermilk and soymilk were 4.82 and 6.60 respectively. The $\mathrm{pH}$ of buttermilk was less as compared soymilk because of its increased acidity. i.e. conversion of lactose into lactic acid. The specific gravity of buttermilk is lower than soymilk because of the lower total solid content. The buttermilk was found to contain moisture $(91.2 \%)$, total solids $(8.8 \%)$ fat $(0.2 \%)$, protein $(3.4 \%)$, total carbohydrate $(4.5 \%)$ and ash $(0.7 \%)$.The soymilk was found to contain moisture $(89.8 \%)$, total solids $(10.2 \%)$ fat $(1.82 \%)$, protein $(3.74 \%)$, total carbohydrate $(3.7 \%)$ and ash (0.94\%). The lactose content of buttermilk was found to contain $4.2 \%$ whereas soymilk is lactose free. The result was good accordance with data of De (2006). The SNF content of buttermilk is $8.76 \%$. The viscosity of soymilk was found to contain 12 cp. The soymilk was found to contain higher amounts of chemical constituents than buttermilk.

\section{Sensory evaluation of flavored lassi}

The panel of 10 trained judges was given samples for evaluation of flavored lassi prepared with various combinations of buttermilk and soymilk. The sensory qualities viz. color and appearance, flavor, body and texture, taste and overall acceptability were evaluated. It was served to judges on the day of preparation of lassi. The average score of flavored lassi recorded by judges were presented in Table 2.

A flavored lassi prepared from composite blends of soymilk and buttermilk was within acceptable range. The sample $\mathrm{C}$ scored higher for all sensory parameters than other treated sample.

\section{Sensory evaluation of flavored lassi powder}

In order to meet the seasonal and regional requirements of lassi, a technology has been developed for the manufacture of lassi powder, which upon reconstitution yields lassi like beverage. The curd is broken by agitation to obtain smooth slurry, which is subsequently spray dried under predetermined conditions. Sugar is dry blended. The powder on reconstitution with water yields lassi-like beverage. The acceptability of beverage could be enhanced by fortification with fruit juices. A dry lassi powder is highly desirable because of long shelf-life, low transportation cost, storage capacity and the product can be distributed over a wide area. Thus, a process for producing a dried lassi powder which is soluble and without loss of nutritive value is 
highly desirable. The panel of trained judges of 10 members was given samples for evaluation of selected flavored lassi powder (Sample C) sensory qualities viz. color and appearance, flavor, body and texture, taste and overall acceptability. It was served to judges on the day of preparation of lassi. The average score recorded by judges was presented in Table 3.

\section{Physico-chemical characteristics of flavored lassi powder}

The flavored lassi powder from sample C scored higher for all sensory parameters was analyzed for physico-chemical characteristics. The results obtained are depicted in Table 4.

The bulk density of flavored lassi powder was $0.3637 \mathrm{~g} / \mathrm{mL}$. The yield of lassi powder was $15 \%$. The moisture content of flavored lassi powder was decreased because of small droplet size and high inlet temperature which led to maximum evaporation of moisture. The protein, fat, carbohydrate and ash content of prepared flavored lassi powder were found 37.8, 13.6, 40.2 was 4.9 and respectively. The color, particle size and titrable acidity of flavored lassi powder was found as $5 \mathrm{Y} 8 / 6$, less than $150 \mu \mathrm{m}$. and $1.08 \%$ respectively.

\section{Nutritional quality of flavored lassi powder}

The flavored lassi powder of sample C, scored higher for all sensory parameters was prepared and was analyzed for its nutrient content. The results obtained are depicted in Table 5.

The flavored lassi powder was found to contain calcium, vitamin $\mathrm{A}$ and phosphorus 280.85 (mg/100g), 92.57 (IU/100g) and $237.39(\mathrm{mg} / 100 \mathrm{~g})$ respectively.

\section{Reconstitution properties of flavored lassi powder}

The reconstitution properties of lassi powder are presented in Table 6 .

The lassi powder prepared from flavored lassi showed good reconstitution properties as water solubility index was found in the range of $92-97 \%$, wettability and sinkability was ranged from $85-95 \%$ and $80-85 \%$. The dispersability of lassi powder ranged from 9095\%. The lassi powder prepared was dispersed easily in water and having good wettability.

Flow sheet.1 Preparation of lassi powder

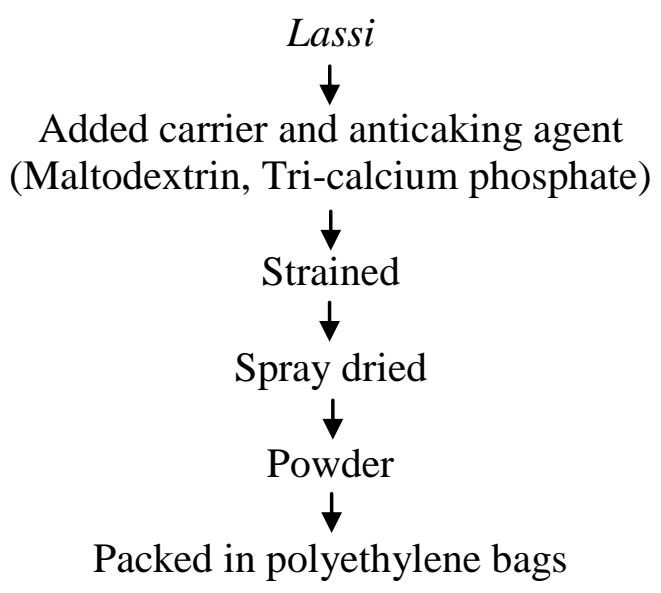


Table.1 Physico-chemical characteristics of buttermilk and soymilk

\begin{tabular}{|l|c|c|}
\hline Parameters & Buttermilk & Soymilk \\
\hline pH & 4.82 & 6.60 \\
\hline Acidity (\%) & 0.50 & 0.17 \\
\hline Specific gravity & 1.015 & 1.055 \\
\hline Moisture (\%) & 91.2 & 89.8 \\
\hline Total solids (\%) & 8.8 & 10.2 \\
\hline Fat (\%) & 0.2 & 1.82 \\
\hline Protein (\%) & 3.4 & 3.74 \\
\hline Total carbohydrate & 4.5 & 3.70 \\
\hline (\%) & & \\
\hline Ash (\%) & 0.7 & 0.94 \\
\hline Lactose (\%) & 4.2 & Nil \\
\hline SNF (\%) & 8.76 & - \\
\hline Viscosity (cp) & - & 12 \\
\hline
\end{tabular}

Table.2 Sensory evaluation of flavored lassi

\begin{tabular}{|c|c|c|c|c|c|}
\hline Sample & $\begin{array}{c}\text { Color and } \\
\text { appearance }\end{array}$ & Flavor & Texture & Taste & $\begin{array}{c}\text { Overall } \\
\text { acceptability }\end{array}$ \\
\hline A (Control) & 9 & 8.5 & 8 & 9 & 8.5 \\
\hline B & 8 & 8 & 8 & 8 & 8 \\
\hline C & 8.5 & 8 & 8.5 & 8.5 & 8.5 \\
\hline D & 7 & 7 & 7 & 7 & 7 \\
\hline SE \pm & 0.033 & 0.033 & 0.026 & 0.028 & 0.028 \\
\hline CD at 5\% & 1.085 & 1.085 & 0.085 & 0.093 & 0.093 \\
\hline
\end{tabular}

Table.3 Sensory evaluation of flavored lassi powder

\begin{tabular}{|c|c|c|c|c|c|}
\hline Sample & $\begin{array}{c}\text { Color and } \\
\text { appearance }\end{array}$ & Flavor & Texture & Taste & $\begin{array}{c}\text { Overall } \\
\text { acceptability }\end{array}$ \\
\hline A (Control) & 7.5 & 8 & 7 & 8.5 & 8.5 \\
\hline C & 7 & 7.5 & 6.5 & 8 & 8 \\
\hline SE \pm & 0.057 & 0.02 & 0.057 & 0.023 & 0.017 \\
\hline CD at 5\% & 2.263 & 1.13 & 2.26 & 0.095 & 0.067 \\
\hline
\end{tabular}

Control - lassi prepared from control lassi powder; C -lassi prepared from sample C. 
Table.4 Physico-chemical characteristics of flavored lassi powder

\begin{tabular}{|c|c|}
\hline Parameters & Value \\
\hline Bulk density $(g / m L)$ & 0.3637 \\
\hline Particle density $\left(\mathrm{g} / \mathrm{cm}^{3}\right)$ & 1.66 \\
\hline Yield $(\%)$ & 15 \\
\hline Moisture (\%) & 3.5 \\
\hline Fat $(\%)$ & 13.6 \\
\hline Protein (\%) & 37.8 \\
\hline Carbohydrate (\%) & 40.2 \\
\hline $\operatorname{Ash}(\%)$ & 4.9 \\
\hline Color & $5 Y 8 / 6$ \\
\hline Particle size $(\mu \mathrm{m})$ & $<150$ \\
\hline Titratable acidity (\%) & 1.08 \\
\hline
\end{tabular}

Table.5 Nutritional quality of flavored lassi powder

\begin{tabular}{|l|c|}
\hline Nutrients & Lassi powder \\
\hline Calcium (mg/100g) & 280.85 \\
\hline Vitamin A (IU/100g) & 92.57 \\
\hline Phosphorus (mg/100g) & 237.39 \\
\hline
\end{tabular}

Table.6 Reconstitution properties of flavored lassi powder

\begin{tabular}{|l|c|c|c|c|}
\hline \multirow{2}{*}{ Parameters } & \multicolumn{4}{|c|}{ Temperature } \\
\cline { 2 - 5 } & $\mathbf{1 0} \mathbf{C}$ & $\mathbf{2 0} \mathbf{C}$ & $\mathbf{3 0} \mathbf{C}$ & $\mathbf{4 0}^{\circ} \mathbf{C}$ \\
\hline Water solubility index (\%) & 90 & 92 & 95 & 97 \\
\hline Wettability (\%) & 85 & 88 & 90 & 95 \\
\hline Sinkability (\%) & 80 & 82 & 85 & 88 \\
\hline Dispersbility (\%) & 90 & 92 & 94 & 96 \\
\hline
\end{tabular}

From the present investigation it can be concluded that, an acceptable low cost flavored lassi powder can be prepared by using soymilk blended with buttermilk can be prepared with addition of sugar (15\%) and mango pulp (5\%). Due to low cost of blended flavored lassi it could have a good market potential. Among the four treatments, treatment $\mathrm{C}$ was found to be more acceptable with respect to mentioned quality parameters. The assessed techno-economic feasibility of prepared product shows to obtain more profits, with in lesser budgets. So technoeconomically it may prove boom, which will open an avenue for lassi market.

\section{References}

Anonymous (2003). Buttermilk: A remedy for many diseases. Indian Dairyman 55: 21.

Avtade, N. B., Wankhede, S. A., and Choudhari, D. M. (2010). Effect of pomegranate juice on chemical quality of lassi. Mysore J. Agric. Sci. 44: 209- 
212.

Balassubramaya, N. N. (2002). Latent milk taurine renders buttermilk-a health drink. In proceedings of ICFOST, Dec.12-13, 2002, CFTRI, Mysore.

De, S. (2006). Outlines of Dairy Technology. In Dairy By- products. Oxford University Press. New Delhi, India, pp. 468.

Fehily, A. M. (2003). Dietary Importance, c.f: Caballero B. et al., (2003) In Encyclopedia of Food Science and Nutrition, $2^{\text {nd }}$ edn. Academic Press, 9: 5392-5394.

GOI (2012). Basic Animal Husbandry Statistics. Department of Animal Husbandry, Dairying and Fisheries, India.

Heiler, C. and Schieberle, P. (1997). Dahi and dahi like products. Int. J. Dairy. Sci. 7: 659-666.

Kadam, P. S., Kalepatil, R. K., Avhad, V. B., Sharma, S. K. and Mote, R. H. (2006). Some studies on preparation of lassi concentrate. J. Soils Crops 16: 121-126.

Kadam, P. S., Kedare, S. D., Ghatge, P. U., and Ingole, A.. J. (2005). Studies on preparation of soya milk blended lassi.
J. Soils Crops. 15: 366-369.

Liu, J. R., Lin, C. W. (2000). Production of kefir from soymilk with or without added glucose, lactose or sucrose. J. Food Sci. 65: 716-719.

Odo, T. (2003) In - Encyclopedia of Food Science and Nutrition, $2^{\text {nd }}$ edition, \{Caballero B, Trugo L. C and Finglas P.M. (eds)\}, Academic Press, 9: 54035406.

Srilakshmi, B. (2003). Food Science. In Nuts and Oilseeds Third Edition, New Age International Publishers, New Delhi, India, pp. 90.

Singh, R. (2007). Characteristics and technology of traditional Indian cultured dairy products. Bulletin of the International Dairy Federation 415: 1120.

Singh, T. P., Santosh Kumari and Sethi, S. (2012). Development of lassi containing aloevera juice and its quality characteristics. J. Dairying, Food and Home Sci. 31: 1-4.

U.S. Soy foods Directory (2007). Insoyfoods.com Soy foods Descriptions tofu.html In- soyfoods.com

\section{How to cite this article:}

Deshpande, H.W., S.L. Waikar and Katke, S.D. 2020. Standardization and Quality Evaluation of Spray Dried Flavored Lassi Powder. Int.J.Curr.Microbiol.App.Sci. 9(08): 273-280. doi: https://doi.org/10.20546/ijcmas.2020.908.032 